\title{
How to predict return to work after lumbar discectomy: answers from the NeuroPoint-SD registry
}

\author{
Khoi D. Than, MD, ${ }^{1}$ Jill N. Curran, MS, ${ }^{2}$ Daniel K. Resnick, MD, ${ }^{3}$ Christopher I. Shaffrey, MD, ${ }^{4}$ \\ Zoher Ghogawala, MD, ${ }^{2}$ and Praveen V. Mummaneni, MD ${ }^{5}$
}

\begin{abstract}
1Department of Neurological Surgery, Oregon Health \& Science University, Portland, Oregon; ${ }^{2}$ Department of Neurosurgery, Lahey Hospital and Medical Center, Burlington, Massachusetts; ${ }^{3}$ Department of Neurological Surgery, University of Wisconsin School of Medicine and Public Health, Madison, Wisconsin; ${ }^{4}$ Department of Neurosurgery, University of Virginia Health System, Charlottesville, Virginia; and ${ }^{5}$ Department of Neurosurgery, University of California, San Francisco, California
\end{abstract}

OBJECTIVE To date, the factors that predict whether a patient returns to work after lumbar discectomy are poorly understood. Information on postoperative work status is important in analyzing the cost-effectiveness of the procedure.

METHODS An observational prospective cohort study was completed at 13 academic and community sites (NeuroPoint-Spinal Disorders [NeuroPoint-SD] registry). Patients undergoing single-level lumbar discectomy were included. Variables assessed included age, sex, body mass index (BMI), SF-36 physical function score, Oswestry Disability Index (ODI) score, presence of diabetes, smoking status, systemic illness, workers' compensation status, and preoperative work status. The primary outcome was working status within 3 months after surgery. Stepwise logistic regression analysis was performed to determine which factors were predictive of return to work at 3 months following discectomy.

RESULTS There were 127 patients (of 148 total) with data collected 3 months postoperatively. The patients' average age at the time of surgery was $46 \pm 1$ years, and $66.9 \%$ of patients were working 3 months postoperatively. Statistical analyses demonstrated that the patients more likely to return to work were those of younger age (44.5 years vs 50.5 years, $p=0.008)$, males $(55.3 \%$ vs $28.6 \%, p=0.005)$, those with higher preoperative SF-36 physical function scores (44.0 vs $30.3, p=0.002)$, those with lower preoperative ODI scores (43.8 vs $52.6, p=0.01)$, nonsmokers $(83.5 \%$ vs $66.7 \%, p=0.03)$, and those who were working preoperatively $(91.8 \%$ vs $26.2 \%, p<0.0001)$. When controlling for patients who were working preoperatively (105 patients), only age was a statistically significant predictor of postoperative return to work (44.1 years vs 51.1 years, $p=0.049$ ).

CONCLUSIONS In this cohort of lumbar discectomy patients, preoperative working status was the strongest predictor of postoperative working status 3 months after surgery. Younger age was also a predictor. Factors not influencing return to work in the logistic regression analysis included sex, BMI, SF-36 physical function score, ODI score, presence of diabetes, smoking status, and systemic illness.

Clinical trial registration no.: 01220921 (clinicaltrials.gov)

http://thejns.org/doi/abs/10.3171/2015.10.SPINE15455

KEY WORDS lumbar discectomy; return to work; prospective registry

$\mathrm{L}$ UMBAR radiculopathy occurs when a fissure in the annulus fibrosus of the intervertebral disc allows herniation of the disc's nucleus pulposus to compress a nearby nerve root, causing radicular motor and sensory symptoms (Fig. 1). The first-line treatments of lumbar radiculopathy are nonoperative measures with medication, physical therapy, and/or steroid injections, as symptoms generally improve on their own after weeks or months. ${ }^{3}$ For patients in whom nonoperative treatments fail, however, surgical decompression of the affected nerve root via hemilaminectomy and discectomy usually provides symptomatic relief.

The prevalence of lumbar radiculopathy is estimated at $3 \%-5 \% .^{15}$ A more recent epidemiological study of a prospectively collected database in the United States military determined the incidence of lumbar radiculopathy to be 4.86 per 1000 person-years in this population. ${ }^{12}$ Risk factors for the development of lumbar radiculopathy included female sex, white race, and age. In the US, approximately 300,000 lumbar discectomies are performed annually,

ABBREVIATIONS BMI = body mass index; HIPAA = Health Insurance Portability and Accountability Act; IRB = institutional review board; NeuroPoint-SD = NeuroPoint-Spinal Disorders; ODI = Oswestry Disability Index; SPORT = Spine Patient Outcomes Research Trial; VAS = visual analog scale.

SUBMITTED April 16, 2015. ACCEPTED October 30, 2015.

INCLUDE WHEN CITING Published online March 18, 2016; DOI: 10.3171/2015.10.SPINE15455. 


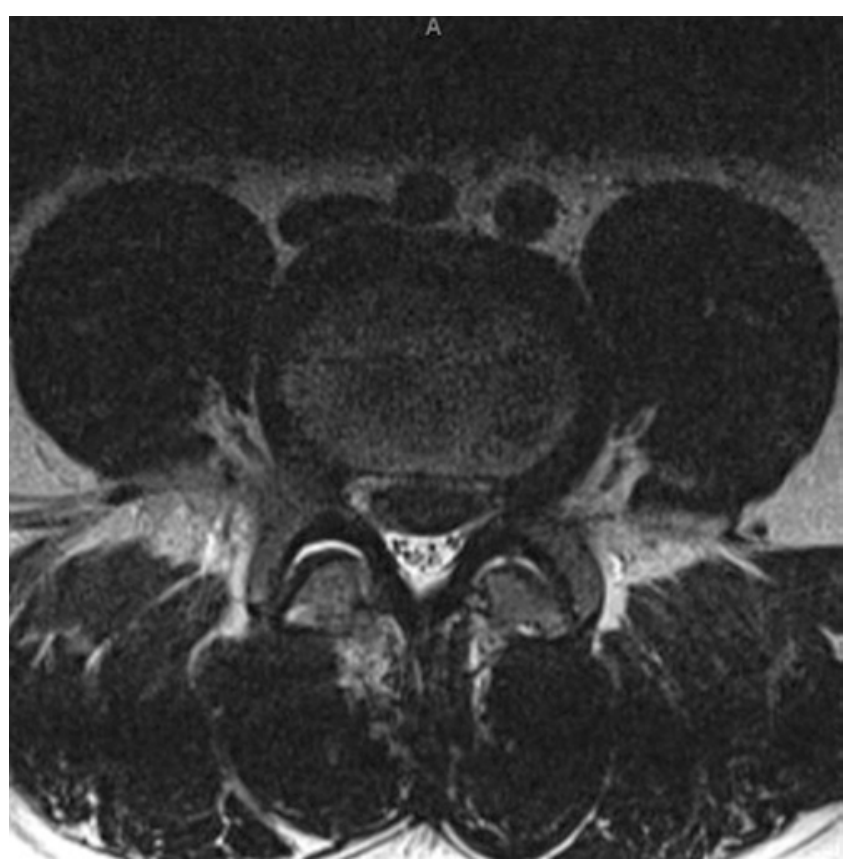

FIG. 1. Axial T2-weighted MR image of a symptomatic L4-5 disc herniation.

making it the most common procedure performed by neurosurgeons and spine surgeons. ${ }^{2,8}$

Despite the common prevalence of lumbar radiculopathy and surgical discectomy, little is known regarding the factors that contribute to the likelihood of a patient returning to employment postoperatively. Certainly, this is information useful for both patients and providers to understand. In this prospective observational cohort study, we seek to identify these factors in hopes that it may help surgeons with surgical patient selection as well as patient counseling.

\section{Methods \\ Study Design}

A prospective, observational cohort registry study enrolled patients from 13 sites (NeuroPoint-Spinal Disorders [NeuroPoint-SD] registry) over a 1-year period and collected data from unselected patients undergoing lumbar discectomy. The registry also included patients undergoing single-level lumbar fusion for spondylolisthesis, but the focus of this manuscript will be on the discectomy patients. Outcomes were measured and observed over a 1 -year period postoperatively. This study was registered with the ClinicalTrials.gov database (http://clinicaltrials. gov), and its registration number is 01220921 .

\section{Data Coordination}

Institutional review board (IRB) approval of the clinical protocol was obtained, and research contracts were executed for this prospective registry at 13 academic and community sites nationwide in September 2010. Sites were selected based on clinical volume and research experience. All sites had a dedicated clinical study coordinator for data collection and entry. Each site study coordinator also reported weekly to a full-time central project manager who supervised the IRB submission, enrollment, and data management at each site. Patient data were managed at the central coordinating center (Wallace Clinical Trials Center in Greenwich, Connecticut). All patient data were de-identified before transfer from each treating institution to protect patient confidentiality, in compliance with the Health Insurance Portability and Accountability Act (HIPAA). All patient data were entered into a secure, HIPAA-compliant, Internet-based data management platform, the NeuroPoint Alliance, which was developed by Outcome Sciences in conjunction with the American Association of Neurological Surgeons. Enrollment occurred over a 1-year period (September 2010 to September 2011). The study data collection was completed in September 2012.

\section{Data Sources and Measurement}

All questionnaires were administered in the outpatient office setting unless the patient was not evaluated in person in the specifically required time frame. In this situation, the questionnaires were mailed to the participants to complete and return to the study site coordinator. Participants completing the questionnaires at home were instructed to call the study site coordinators to address any questions. In addition, site coordinators reviewed the questionnaires for completeness. To incentivize the completion of the study questionnaires, each participant was given $\$ 25$ for the completion of the outcomes instruments at each time point. Participants were contacted via phone to assess work status, to document any complications during the study period, and to address and complete any missing data from the questionnaires. Each patient who failed to return follow-up questionnaires was contacted 3 times via mail and/ or phone call to ensure maximal patient compliance.

\section{Study Population}

Patients 18-80 years old, with symptomatic lumbar disc herniation recalcitrant to noninvasive therapies for at least 6 weeks, were eligible. Patients were excluded for any of the following reasons: 1) history of previous lumbar spinal surgery at the level of disc herniation; 2) significant motor weakness on manual muscle testing of $3 / 5$ or less (such as foot drop) or cauda equina syndrome; 3) cancer, infection, or fracture involving any portion of the spine; and 4) pregnancy. Each site was permitted to enroll up to 25 (unselected) patients within the 1-year study period.

Patients were recruited from 13 sites without regard to sex, race, age, language preference, or socioeconomic status. There was no specific advertising to recruit patients, although the clinical registry was listed with www. clinicaltrials.gov and on most of the participating institutions' clinical research Web pages. All potentially eligible patients were screened by a study coordinator for possible enrollment. A screening log was maintained by a study coordinator at each site. All patients who were eligible and who agreed to participate were asked to sign an IRBapproved consent form to participate in the study. The patient's treatment was not affected in any way by choosing not to participate in the study. 


\section{Outcomes Assessment}

The primary outcome assessed for this manuscript was whether a patient was employed at 3 months following their lumbar discectomy.

The primary end point of the overall study was the physical function domain from the general health-related quality of life measure: the RAND Medical Outcomes Study SF-36 (36-Item Short-Form Health Survey). ${ }^{6}$ A secondary outcome was the percentage of patients who completed all outcome assessments during the 1-year study period at each site as well as the overall study-wide compliance in obtaining patient-reported outcome assessments. It was expected that all sites would have at least an $80 \%$ compliance rate for the completion of all outcome questionnaires during the 1-year study period.

Patients completed 1 disease-specific outcome measure, the Oswestry Disability Index (ODI) ${ }^{4} ; 1$ general health-related quality of life measure, the norm-based SF-36 $6^{6}$ and the visual analog scale (VAS) ${ }^{5}$ for back pain, all preoperatively and at $1,3,6$, and 12 months postoperatively. Return to work and complication assessments were completed by an independent study coordinator at each site. Complications included all major adverse events (death, myocardial infarction, pulmonary embolus, infection, cerebrospinal fluid leakage, new neurological deficit [such as foot drop], readmission, and reoperation). Delayed complications (such as reoperation, fusion complications, problems with instrumentation, and deformity) were recorded at 1 year.

\section{Covariates}

We collected baseline demographic information including age, sex, insurance type, work status, and baseline health status measures on all patients. Disability status was not collected per se, but patients did classify themselves as "disabled, unable to work," "not working but able to do so," "not working but looking for work," and "working."

\section{Surgical Treatment}

All patients underwent surgery at the discretion of the surgeon and patient. Patient symptoms (i.e., low back pain vs radiculopathy) were not analyzed. Lumbar discectomy was performed as previously described. ${ }^{14}$ Differences in surgical technique (i.e., minimally invasive vs open, extent of discectomy) were not analyzed.

\section{Study Sample Size Estimates}

Based on the published data for the lumbar discectomy patients from the Spine Patient Outcomes Research Trial (SPORT) ${ }^{16}$ we assumed a preoperative value of 30 for SF36 physical function, with a standard deviation between 23 and 25, and a treatment effect consisting of a 40- to 45-point improvement. To achieve a significant level of 5\% in a 2-sided test, we calculated that a sample size of 10 patients per site would be necessary to demonstrate the effectiveness of lumbar discectomy at $80 \%$ power, leading to the total sample size estimate for the lumbar discectomy cohort of 100 patients. Of note, the study was designed to have only 10 sites participate, but 13 sites were enrolled as a precaution in the event that any site was un- able to complete the IRB/contract process in sufficient time. Some sites completed this process more slowly than others; thus, the inclusion of additional sites allowed the enrollment goal to be attained over the 1-year period. The sample size was increased to 125 patients to accommodate attrition during follow-up. However, enrollment concluded and the analysis was initiated at the end of the 1-year enrollment period, not when 125 patients had been accrued. Sample size calculations were not specifically performed for the analysis of return to work data.

\section{Statistical Analysis}

A $p$ value $<0.05$ was considered statistically significant. Analyses were performed using the statistical program Stata 12.1. Stepwise logistic regression analysis, using a threshold $p$ value of 0.35 , was used to identify the predictors affecting a patient's ability to return to work at 3 months postoperatively.

\section{Results \\ Patient Population}

A total of 249 patients were screened and 198 were enrolled from 13 academic and community sites (mean 15 patients per site) over 1 year. Of the 198 enrolled patients, 148 had undergone lumbar discectomy and data from their cases were analyzed in this manuscript. The number of patients enrolled in the study from each de-identified center is presented in Table 1. Fifty patients underwent lumbar fusion for spondylolisthesis and, therefore, were not included in this analysis. The median age of discectomy patients was 45 years, the median body mass index (BMI) was 27.3 $\mathrm{kg} / \mathrm{m}^{2}, 49 \%$ of patients were female, $2 \%$ had diabetes, and $21 \%$ were smokers (Table 2). Data on duration of symptoms and nonoperative modalities attempted were not collected.

\section{Compliance and Database Auditing}

Overall, there was $88.3 \%$ compliance (site range $25 \%-$ 97.3\%) with patient-reported outcome data collection. The

TABLE 1. Number of lumbar discectomy patients whose data were contributed by each of the centers involved in this study

\begin{tabular}{cc}
\hline Center & No. of Patients \\
\hline 1 & 23 \\
\hline 2 & 17 \\
\hline 3 & 15 \\
\hline 4 & 15 \\
\hline 5 & 14 \\
\hline 7 & 13 \\
\hline 8 & 12 \\
\hline 9 & 11 \\
\hline 10 & 9 \\
\hline 11 & 8 \\
\hline 12 & 6 \\
\hline 13 & 3 \\
\hline
\end{tabular}


TABLE 2. Summary statistics of the lumbar discectomy cases obtained from the NeuroPoint-SD registry

\begin{tabular}{cc}
\hline Variable & Value \\
\hline No. of patients & 148 \\
\hline Age in years & 45.0 \\
\hline Median & $37.0-54.0$ \\
\hline IQR & 27.3 \\
\hline BMI, kg/m ${ }^{2}$ & $23.6-30.9$ \\
\hline Median & $72(48.7)$ \\
\hline IQR & $3(2.0)$ \\
\hline Female, $\mathrm{n}(\%)$ & $31(21.0)$ \\
\hline Diabetes, $\mathrm{n}(\%)$ & \\
\hline Smoker, $\mathrm{n}(\%)$ & 44.0 \\
\hline Baseline score & $34.0-60.0$ \\
\hline ODI & \\
\hline Median & 35.0 \\
\hline IQR & $20.0-55.0$ \\
\hline SF-36 & 7.0 \\
\hline Median & $4.0-8.5$ \\
\hline IQR & \\
\hline VAS & \\
\hline Median & \\
\hline IQR & \\
\hline
\end{tabular}

$\mathrm{IQR}=$ interquartile range.

average period of enrollment at each site was 7.5 months. Target enrollment was capped at a maximum of 25 patients per site. Baseline evaluations were completed in all patients (100\%). Outcome assessment compliance (followup) was $87.4 \%, 86.9 \%$, and $83.3 \%$ at 3,6 , and 12 months, respectively. There was $96 \%$ compliance in obtaining complications data at 30 days. At 1 year, there was $83.3 \%$ compliance in completing an independent complications assessment. Four patients did not complete any questionnaires after initial enrollment. One patient died 3 months following surgery, but the death was unrelated to surgery.

\section{Return to Work}

A total of 105 patients with disc herniation (70.9\%) were working preoperatively. The average time of missed work was 67 days for lumbar discectomy patients.

After we arbitrarily selected the 3-month time point to identify predictors of return to work, 127 of 148 cases were available for analysis. Eighty-five of these patients (66.9\%) were working at 3 months postoperatively (of these, 78 were working preoperatively and 7 were not). Of the 42 patients who were not working at 3 months, 31 were not working preoperatively and 11 were. Of the 127 patients with 3-month work status available, 27 were not working preoperatively due to being "disabled, unable to work." At 3 months, 11 of these patients were still "disabled, unable to work," 5 were "not working but able to do so," 4 were "not working but looking for work," and 7 were "working." There were 6 more patients who classified themselves as "disabled, unable to work" at 3 months
TABLE 3. Comparison of factors in patients working and not working 3 months after lumbar discectomy*

\begin{tabular}{|c|c|c|c|}
\hline Variable & $\begin{array}{c}\text { Working at } 3 \\
\text { Months }(n=85)\end{array}$ & $\begin{array}{l}\text { Not Working at } 3 \\
\text { Months }(n=42)\end{array}$ & $p$ Value \\
\hline Age in years, mean & $44.45 \pm 10.84$ & $50.45 \pm 13.60$ & 0.008 \\
\hline Male sex, n (\%) & $47(55.3)$ & $12(28.6)$ & 0.005 \\
\hline $\mathrm{BMI}$ in $\mathrm{kg} / \mathrm{m}^{2}$, mean & $27.76 \pm 5.54$ & $28.25 \pm 4.60$ & 0.6283 \\
\hline Preop SF-36, mean & $43.96 \pm 23.54$ & $30.32 \pm 21.53$ & 0.002 \\
\hline Preop ODI, mean & $43.82 \pm 17.16$ & $52.60 \pm 19.13$ & 0.01 \\
\hline Diabetes, n (\%) & $1(1.2)$ & $2(4.8)$ & 0.254 \\
\hline Smoker, n (\%) & $14(16.5)$ & $14(33.3)$ & 0.031 \\
\hline Systemic illness, n (\%) & $7(8.2)$ & $3(7.1)$ & 1.00 \\
\hline $\begin{array}{l}\text { Workers' compensa- } \\
\text { tion, } n(\%)\end{array}$ & $0(0)$ & $1(2.4)$ & 0.331 \\
\hline $\begin{array}{l}\text { Working preopera- } \\
\text { tively, } \mathrm{n}(\%)\end{array}$ & 78 (91.8) & $11(26.2)$ & $<0.0001$ \\
\hline
\end{tabular}

postoperatively; 3 of these patients were "working" preoperatively, and 3 were "not working but able to do so."

When analyzing for age, sex, BMI, preoperative SF-36 score, preoperative ODI score, presence of diabetes or systemic illness, smoking status, workers' compensation status, and preoperative work status, younger age, male sex, higher preoperative SF-36 score, lower preoperative ODI score, nonsmokers, and patients working preoperatively were more likely to return to work 3 months after lumbar discectomy. This information is displayed in Table 3.

Logistic regression analysis demonstrated that the only variables to independently predict return to work 3 months after discectomy were male sex and preoperative work status (Table 4). The regression model, however, appeared to be predominantly influenced by preoperative work status, so it was decided to perform a subgroup analysis of only patients who were working preoperatively.

Of the 127 patients available for analysis at 3 months, 89 were working preoperatively. Of these, $78(87.6 \%)$ had returned to work at 3 months, while 11 had not. Of the same variables analyzed above, only age was significantly associated with eventually returning to work $(\mathrm{p}=0.049)$. These results are displayed in Table 5. In a logistic regression analysis of this subgroup, age continued to be the only statistically significant predictor of postoperative return to work $(\mathrm{p}=0.029)$ (Table 6$)$. Of note, of the 38 patients who were not working preoperatively, only 7 of them $(18.4 \%)$ were working 3 months postoperatively.

Data available at 6 months and 1 year following lumbar discectomy revealed that, in patients who were working preoperatively, $89.3 \%$ had resumed work at 6 months and $93.8 \%$ had resumed work at 1 year. In patients who were not working preoperatively, $18.4 \%$ were working at 3 months, $22.9 \%$ at 6 months, and $45.5 \%$ at 12 months. In all lumbar discectomy patients, the percentage of patients working was $66.9 \%$ at 3 months, $69.7 \%$ at 6 months, and $78.6 \%$ at 12 months. These data are represented graphically in Fig. 2. 
TABLE 4. Results of multivariate logistic regression analysis*

\begin{tabular}{lcccc}
\hline \multicolumn{1}{c}{ Covariate } & OR & SE & p Value & $95 \% \mathrm{Cl}$ \\
\hline Age & 0.96 & 0.03 & 0.109 & $0.91-1.01$ \\
\hline Male sex & 0.10 & 0.07 & $\mathbf{0 . 0 0 1}$ & $0.02-0.42$ \\
\hline Preop SF-36 & 1.02 & 0.02 & 0.325 & $0.98-1.05$ \\
\hline Preop ODI & 1.04 & 0.02 & 0.114 & $0.99-1.09$ \\
\hline Smoking status & 3.65 & 2.44 & 0.052 & $0.99-13.50$ \\
\hline Preop working status & 76.61 & 65.64 & $<\mathbf{0 . 0 0 1}$ & $14.29-410.82$ \\
\hline
\end{tabular}

* Boldface type indicates statistical significance.

\section{Discussion}

In this study, we found that the factors most predictive of a patient's ability to return to work within 3 months following lumbar discectomy are whether he/she was working preoperatively and is of a younger age. Nearly $88 \%$ of patients who were working preoperatively were able to return to work at 3 months, while only $18 \%$ of patients who were not working did so. The average time of work lost was 2 months. We believe that this is important information to divulge when counseling lumbar discectomy patients.

Few studies thus far have looked specifically at the predictors of return to work following lumbar discectomy. Nearly 2 decades ago, Rompe et al. ${ }^{11}$ retrospectively analyzed (via questionnaire) 101 patients at a mean of 10.2 years following their lumbar discectomy. Fortyfour $(43.6 \%)$ of the 101 patients were working full time in their usual job 1 decade after their discectomy. Of the 57 remaining patients, 9 were working a lighter full-time job and 18 were working part time, yielding a total of 71 working patients $(70.3 \%)$. Patients working full time in their usual job were significantly younger, less obese, had fewer neurological deficits, had a shorter time from presentation to operation, had undergone fewer reoperations,

TABLE 5. Comparison of factors in patients working and not working 3 months after lumbar discectomy in those who were working preoperatively*

\begin{tabular}{lccc}
\hline \multicolumn{1}{c}{ Variable } & $\begin{array}{c}\text { Working at 3 } \\
\text { Months }(\mathrm{n}=78)\end{array}$ & $\begin{array}{c}\text { Not Working at 3 } \\
\text { Months }(\mathrm{n}=11)\end{array}$ & $\mathrm{p}$ Value \\
\hline Age in years, mean & $44.13 \pm 10.81$ & $51.09 \pm 10.92$ & $\mathbf{0 . 0 4 9 0}$ \\
\hline Male sex, $\mathrm{n}(\%)$ & $40(51.3)$ & $3(27.3)$ & 0.199 \\
\hline BMl in kg/m², mean & $27.32 \pm 5.42$ & $28.85 \pm 3.95$ & 0.3710 \\
\hline Preop SF-36, mean & $45.26 \pm 23.49$ & $40.30 \pm 19.60$ & 0.5069 \\
\hline Preop ODI, mean & $42.67 \pm 17.00$ & $37.09 \pm 15.27$ & 0.3053 \\
\hline Diabetes, $\mathrm{n}(\%)$ & $1(1.3)$ & $1(9.1)$ & 0.233 \\
\hline Smoker, $\mathrm{n}(\%)$ & $12(15.4)$ & $4(36.4)$ & 0.105 \\
\hline $\begin{array}{l}\text { Systemic illness, } \mathrm{n}(\%) \\
\text { Workers' compensa- } \\
\text { tion, } \mathrm{n}(\%)\end{array}$ & $6(7.7)$ & $0(0)$ & 1.00 \\
\hline
\end{tabular}

* Mean values are presented \pm SD. Boldface type indicates statistical significance.
TABLE 6. Multivariate logistic regression analysis to assess the likelihood of return to work based on the presence of a given variable including only patients who were working preoperatively

\begin{tabular}{lcccc}
\hline \multicolumn{1}{c}{ Covariate } & OR & SE & p Value & $95 \% \mathrm{Cl}$ \\
\hline Age & 0.92 & 0.04 & 0.029 & $0.85-0.99$ \\
\hline Male sex & 0.22 & 0.18 & 0.064 & $0.04-1.09$ \\
\hline BMI & 0.90 & 0.07 & 0.156 & $0.78-1.04$ \\
\hline Preop SF-36 & 1.03 & 0.02 & 0.235 & $0.98-1.08$ \\
\hline Preop ODI & 1.06 & 0.03 & 0.063 & $0.997-1.13$ \\
\hline Smoking status & 4.37 & 3.73 & 0.084 & $0.82-23.27$ \\
\hline
\end{tabular}

and were employed in less physically demanding jobs. The primary shortcoming of this study is that it assessed patient employment 1 decade after surgery, whereas patients are presumably more interested in their ability to return to work in the shorter term.

A more recent study carried out in Germany and involving 182 patients analyzed predictors of return to work at 6 months postoperatively in patients who underwent nucleotomy. ${ }^{7}$ The predictors of return to work after multiple regression analysis included job satisfaction, preoperative sick leave of less than 6 weeks, and low preoperative pain. Similarly, a prospective Swedish study found that $89 \%$ of patients who underwent lumbar discectomy were working in some capacity 2 years after surgery. ${ }^{13}$ The factors predictive of return to work at 2 years included a shorter duration of leg pain (less than 6 months) and less time spent on sick leave preoperatively (less than 2 months).

It is important to note that in our total population of 127 patients, only 1 patient was receiving workers' compensation; our subgroup analyses included no patients receiving workers' compensation. Thus, based on this study, it is difficult to draw conclusions on the effect of workers' compensation status on return to work after lumbar discectomy. The recent literature does suggest that patients with workers' compensation claims do have poorer outcomes following lumbar discectomy. The SPORT ${ }^{1}$ prospectively analyzed 113 patients with workers' compensation claims and 811 patients without. At the 2-year follow-up, patients not receiving workers' compensation who underwent lumbar discectomy had better outcomes based on SF-36 bodily

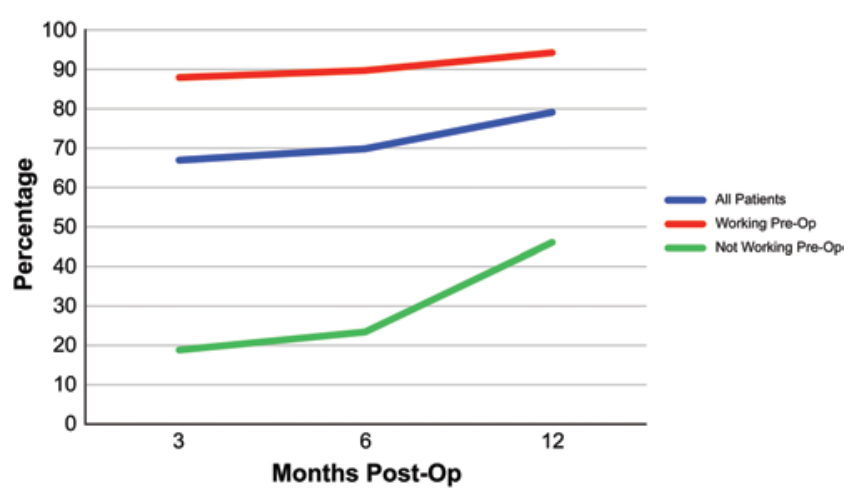

FIG. 2. Percentage of lumbar discectomy patients working postoperatively. Figure is available in color online only. 
pain and physical function scores compared with patients also not receiving worker's compensation who were treated nonoperatively. Conversely, in cases involving workers' compensation, patients treated surgically did not have these improved outcomes. A review of 11 subgroup analyses in the SPORT further suggested that patients without workers' compensation claims have better outcomes after either surgical or nonoperative treatment of lumbar disc herniation than patients with workers' compensation claims. ${ }^{9}$ Insurance status was not assessed in that study.

The limitations of this study include its relatively small sample size of 148 total lumbar discectomy patients and the short follow-up duration of 1 year. Since overall compliance was $88.3 \%$ (and not $100 \%$ ), there exists the small possibility of confounding bias given a particular site's high or low compliance rate. Since individual surgeons and patients decided upon surgery, imaging studies were not reviewed for this manuscript and so the size, location, and appearance of the disc herniations are unknown, potentially affecting outcomes. Any differences in surgical indications and/or technique that could affect outcomes were also not assessed. However, it should be noted that minimally invasive and open discectomies have not been shown to be significantly different in prior studies. ${ }^{10}$ Given that older patients were less likely to return to work, one limitation is the fact that we did not assess whether older patients simply chose to retire. Two important influences of return to work-patients' motivation to return to work and surgeon influence on patients - could not be assessed. Larger scale prospective registries, namely the National Neurosurgery Quality and Outcomes Database (N2QOD), will certainly be able to address these limitations in future studies. This NeuroPoint-SD registry was a pilot registry for spine (one of the first of its kind), and the lessons we learned will be applied to larger scale studies in the future.

\section{Conclusions}

In this prospective registry study utilizing the NeuroPoint-SD database, the factor most predictive of a lumbar discectomy patient's ability to return to work is whether he or she was working preoperatively. Younger age was also predictive of return to work. This is important information to understand when counseling patients preoperatively. Future, larger studies are likely to provide further information on the predictors of return to work.

\section{References}

1. Atlas SJ, Tosteson TD, Blood EA, Skinner JS, Pransky GS, Weinstein JN: The impact of workers' compensation on outcomes of surgical and nonoperative therapy for patients with a lumbar disc herniation: SPORT. Spine (Phila Pa 1976) 35:89-97, 2010

2. Bruske-Hohlfeld I, Merritt JL, Onofrio BM, Stonnington $\mathrm{HH}$, Offord KP, Bergstralh EJ, et al: Incidence of lumbar disc surgery. A population-based study in Olmsted County, Minnesota, 1950-1979. Spine (Phila Pa 1976) 15:31-35, 1990

3. Casey E: Natural history of radiculopathy. Phys Med Rehabil Clin N Am 22:1-5, 2011

4. Fairbank JC, Couper J, Davies JB, O'Brien JP: The Oswestry Low Back Pain Disability Questionnaire. Physiotherapy 66:271-273, 1980

5. Gallagher EJ, Liebman M, Bijur PE: Prospective validation of clinically important changes in pain severity measured on a visual analog scale. Ann Emerg Med 38:633-638, 2001

6. Hays RD, Sherbourne CD, Mazel RM: The RAND 36-Item Health Survey 1.0. Health Econ 2:217-227, 1993

7. Kitze K, Winkler D, Günther L, Angermeyer MC: Preoperative predictors for the return to work of herniated disc patients. Zentralbl Neurochir 69:7-13, 2008

8. Koebbe CJ, Maroon JC, Abla A, El-Kadi H, Bost J: Lumbar microdiscectomy: a historical perspective and current technical considerations. Neurosurg Focus 13(2):E3, 2002

9. Koerner JD, Glaser J, Radcliff K: Which variables are associated with patient-reported outcomes after discectomy? Review of SPORT disc herniation studies. Clin Orthop Relat Res 473:2000-2006, 2014

10. Rasouli MR, Rahimi-Movaghar V, Shokraneh F, MoradiLakeh M, Chou R: Minimally invasive discectomy versus microdiscectomy/open discectomy for symptomatic lumbar disc herniation. Cochrane Database Syst Rev 9:CD010328, 2014

11. Rompe JD, Eysel P, Zöllner J, Heine J: Prognostic criteria for work resumption after standard lumbar discectomy. Eur Spine J 8:132-137, 1999

12. Schoenfeld AJ, Laughlin M, Bader JO, Bono CM: Characterization of the incidence and risk factors for the development of lumbar radiculopathy. J Spinal Disord Tech 25:163-167, 2012

13. Silverplats K, Lind B, Zoëga B, Halldin K, Rutberg L, Gellerstedt M, et al: Clinical factors of importance for outcome after lumbar disc herniation surgery: long-term follow-up. Eur Spine J 19:1459-1467, 2010

14. Spengler DM: Lumbar discectomy. Results with limited disc excision and selective foraminotomy. Spine (Phila Pa 1976) 7:604-607, 1982

15. Tarulli AW, Raynor EM: Lumbosacral radiculopathy. Neurol Clin 25:387-405, 2007

16. Weinstein JN, Lurie JD, Tosteson TD, Skinner JS, Hanscom B, Tosteson AN, et al: Surgical vs nonoperative treatment for lumbar disk herniation: the Spine Patient Outcomes Research Trial (SPORT) observational cohort. JAMA 296:2451-2459, 2006

\section{Disclosures}

Dr. Shaffrey reports being a consultant and holding patents and receiving royalties with Biomet, Medtronic, and NuVasive and being a consultant with K2M and Stryker. Dr. Mummaneni reports holding direct stock ownership in Spinicity/ISD; receiving royalties from DePuy Synthes, Springer Publishing, Thieme, and Taylor and Francis Publishers; and receiving honoraria and fellowship institutional grants from AOSpine and Globus.

\section{Author Contributions}

Conception and design: all authors. Acquisition of data: Curran. Analysis and interpretation of data: Than, Curran, Resnick, Shaffrey, Ghogawala. Drafting the article: Than. Critically revising the article: all authors. Reviewed submitted version of manuscript: all authors. Approved the final version of the manuscript on behalf of all authors: Than. Statistical analysis: Curran.

\section{Supplemental Information}

\section{Previous Presentations}

Portions of this work were presented at the 31st Annual Meeting of the AANS/CNS Joint Section on Disorders of the Spine and Peripheral Nerve, in Phoenix, Arizona, March 4-7, 2015.

\section{Correspondence}

Khoi D. Than, Department of Neurological Surgery, Oregon Health \& Science University, CH8N, 3303 S.W. Bond Ave., Portland, OR 97239. email: thank@ohsu.edu. 